\title{
Clinical Impact of Universal Screening for COVID-19 before Therapeutic Endoscopy
}

\author{
Nitin Jagtap ${ }^{1, \odot}$ Aniruddha Pratap Singh ${ }^{1}$ Pradev Inavolu ${ }^{1} \quad$ Manu Tandan ${ }^{1} \quad$ Sundeep Lakhtakia ${ }^{1, \odot}$ \\ D Nageshwar Reddy ${ }^{1}$
}

${ }^{1}$ Department of Gastroenterology, Asian Institute of Gastroenterology, Hyderabad, India

\begin{abstract}
Address for correspondence Nitin Jagtap, MD, DNB, Department of Gastroenterology, Asian Institute of Gastroenterology, Hyderabad, India (e-mail: docnits13@gmail.com).
\end{abstract}

J Digest Endosc:2020;11:270-274

\begin{abstract}
Introduction The Coronavirus pandemic (COVID-19) has led to drastic change in gastrointestinal (Gl) endoscopy practice. Endoscopy is an aerosol-generating procedure. COVID-19 testing prior to endoscopy can reduce transmission by delaying non-emergency endoscopies in positive patients. There is scarcity of literature to support such protocols. We aimed to study the clinical impact of universal testing for COVID-19 before therapeutic endoscopy.

Methods This is retrospective analysis of prospectively maintained data. All patients requiring therapeutic endoscopy were enrolled between June 15 to July 15, 2020 . Clinical profile, indication, endoscopic intervention, and outcome of patients tested positive for COVID-19 real-time polymerase chain reaction (RT PCR) or CT chest suggestive of CO-RADS 3 or more were included for analysis.

Results Out of 772 patients scheduled for endoscopic interventions, 26 (3.34\%) patients had COVID-19 infection with mean age (range) of 48.19 (3-75) years. Eight (30.8\%) were females. Of them, seven (26.9\%) patients underwent emergency endoscopy, and another seven (26.9\%) patients underwent endoscopy after minimum of 2 weeks waiting period. Two deaths were seen in patients who underwent emergency interventions which were unrelated to endoscopy. One patient, who was planned for endoscopic ultrasound (EUS) for choledocholithiasis, developed acute biliary pancre-

Keywords

- COVID-19

- endoscopy

- screening

- safety

- adverse events atitis in the waiting period.

Conclusion We suggest use of universal testing for COVID-19 by RT-PCR before endoscopic intervention. Endoscopy can be postponed for 2 weeks with marginal risk of adverse events during the waiting period in nonemergency indications. However, this approach needs to be tailored as per local needs, resources availability, and indication of endoscopy.
\end{abstract}

\section{Introduction}

Since the onset of Coronavirus disease 2019 (COVID-19), pandemic protocols for performing endoscopic procedures have been recommended by various gastrointestinal (GI) societies. ${ }^{1-3}$ These guidelines have suggested protocols for infection prevention and control, triage, isolation, use of personal protection equipment (PPE) along with use of testing to reduce the burden of COVID-19 among health care
DOI https://doi.org/ $10.1055 / \mathrm{s}-0040-1722378$ ISSN 0976-5042. (c) 2020. Society of Gastrointestinal Endoscopy of India.

This is an open access article published by Thieme under the terms of the Creative Commons Attribution-NonDerivative-NonCommercial-License, permitting copying and reproduction so long as the original work is given appropriate credit. Contents may not be used for commercial purposes, or adapted, remixed, transformed or built upon. (https://creativecommons.org/licenses/by-nc-nd/4.0/).

Thieme Medical and Scientific Publishers Pvt. Ltd. A-12, 2nd Floor, Sector 2, Noida-201301 UP, India 
professionals. ${ }^{1,4}$ However, these protocols need to adopted and modified according to local need, availability, and affordability of resources. ${ }^{5,6}$ The prioritization of GI endoscopy according to protocols and indications has resulted in endoscopic centers to operate at less than $25 \%$ of normal volume. ${ }^{3,-9}$ As endoscopic procedures are considered to be aerosol-generating procedures, guidelines have advised screening of all patients for COVID-19 prior to endoscopy, in order to prevent COVID-19 transmission. ${ }^{1,2,6,10}$ There is risk of transmission of COVID-19 infection from asymptomatic carriers who need endoscopic intervention to health care workers. ${ }^{11-13}$

Previous reports have shown positivity rate for COVID-19 of 0.20 to $0.96 \%$ in patients undergoing GI endoscopy. ${ }^{14,15}$ This proportion may be lower than general population but expected to change over time as the pandemic is still evolving. A computer model-based study evaluated three approach strategies: urgent endoscopy only without testing, COVID-19 testing for semiurgent indication, and testing all patients. This model conclude that COVID-19 real-time polymerase chain reaction (SARS-CoV-2 RT-PCR) testing would be effective strategy to restart endoscopy units. ${ }^{6}$ At present, India has the third highest total COVID-19 case burden and third highest daily new cases in the world after USA and Brazil. COVID-19 testing is being performed by various centers prior to endoscopy. In the event of a patient testing positive, procedures will be postponed for at least 14 days, unless the endoscopic procedure is considered as an emergency. ${ }^{14}$ However, there is scarcity of literature to support safety and effectiveness of such protocols. Previous reports have not addressed the issue of safety of postponing the nonemergent procedures. ${ }^{14,15}$

We aimed to evaluate clinical impact of pre endoscopy COVID-19 testing with SARS-CoV-2 RT PCR at a large tertiary care center.

\section{Methods}

Institutional review board approval was taken. In this retrospective analysis of prospectively maintained data, all patients requiring endoscopic interventions at a large tertiary care center from June 15 to July 15, 2020, were screened. All patients requiring endoscopic interventions were interviewed for clinical and epidemiological screening for COVID-19 symptoms by trained staff. These patients were categorized into emergency and nonemergency, depending on indication for endoscopy. All patients requiring endoscopic interventions were advised to undergo COVID-19 RT-PCR testing. In case of patients refusing COVID-19 testing, a detailed counselling by endoscopists was conducted. In case of persistent refusal to test for COVID-19 or for procedures with emergency indications, procedure was performed with full PPE worn by all endoscopy staff. For RT-PCR testing, both nasal and nasopharyngeal swabs were taken.

Emergency endoscopies were performed within 24 hours of admission by senior endoscopists along with dedicated staff and anesthesiologist. If clinically indicated, emergency endoscopic intervention was performed before RT-PCR test result was available. In case the patient requiring emergency endoscopy was at high risk of COVID-19 infection, CT chest screening was used for urgent triaging in absence of RT-PCR results. For nonemergency indications, endoscopy was scheduled after RT PCR testing. Irrespective of test results, all endoscopic procedures were performed as per guidelines. ${ }^{2,5}$

If the test is positive, procedures were postponed for at least 14 days, unless considered as emergency. In case of high suspicion of COVID-19 in RT-PCR negative patients, depending on clinical and epidemiological factors such as residence of high prevalence area, contact and travel history, patients underwent $\mathrm{CT}$ chest screening before endoscopy. In case CT showed (COVID-19 reporting and data systems) CO-RADS 3 or more, these patients underwent either repeat RT-PCR or procedure was postponed for 2 weeks, if no emergency. All patients who were COVID-19 RT-PCR positive or who had CT CO-RADS score 3 or more were considered as COVID-19 patients. ${ }^{16}$ These patients were kept under isolation where they were closely monitored for worsening of COVID-19 or underlying GI illness. Any adverse event in those patients was noted.

All hospital staffs including endoscopy staff were educated about universal precautions, safety measures, and COVID-19 symptoms. They were screened daily for COVID-19 related symptoms. RT PCR testing were performed in case of symptoms or in case of contact with COVID-19 patient. Additionally, we have performed random COVID-19 RT PCR testing in 5\% hospital staff weekly.

\section{Results}

A total of 772 patients were posted for various endoscopic interventions between June 15 to July 15, 2020 ( - Fig. 1). Of these, 26 (3.34\%) patients had COVID-19 infection with mean age (range) of 48.19 (3-75) years. Eight (30.8\%) were females. - Table 1 depicts overview of each endoscopic procedure and outcome. RT PCR was positive in 3.1\% (24/772). Fifty-seven patients underwent $\mathrm{CT}$ chest due to high clinical suspicions of COVID-19 despite negative RT-PCR. In two patients, CT chest was suggestive of CO-RADS 3 and 5 and RT PCR was negative. Of these 26 patients, 7 (26.9\%) patients underwent emergency endoscopy, and another 7 (26.9\%) patients underwent endoscopic intervention after a minimum of 2 weeks of waiting period ( - Table 2 ). Five of seven underwent

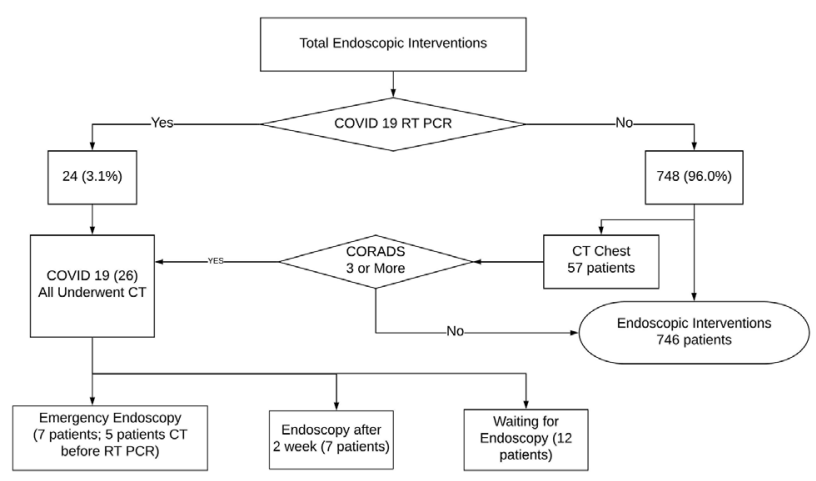

Fig. 1 Flowchart of patients. 
Table 1 Overview of various procedures in COVID-19 patients

\begin{tabular}{|l|l|l|l|l|l|l|}
\hline Endoscopy & $\begin{array}{l}\text { Total } \\
\text { procedure }\end{array}$ & COVID-19 & Emergency & Postponed & $\begin{array}{l}\text { Procedure } \\
\text { after 2 weeks }\end{array}$ & Adverse event \\
\hline ERCP & 351 & 6 & 2 & 4 & 2 & 1 Death \\
\hline EUS & 174 & 4 & 0 & 4 & 3 & 1 Acute pancreatitis \\
\hline UGIE & 223 & 12 & 3 & 9 & 2 & 1 Death \\
\hline Colonoscopy & 24 & 4 & 2 & 2 & Nil & Nil \\
\hline Total & 772 & $26(3.34)^{\mathrm{a}}$ & $7(26.9)^{\mathrm{b}}$ & $19(73.1)^{\mathrm{b}}$ & $7(26.9)^{\mathrm{b}}$ & $\begin{array}{l}2 \text { Deaths } \\
1 \text { Acute pancreatitis }\end{array}$ \\
\hline
\end{tabular}

Abbreviations: ERCP, endoscopic retrograde cholangiopancreatography; EUS, endoscopic ultrasound; UGIE, upper gastrointestinal endoscopy. Figures in parenthesis are percentages.

apercentage of total procedures, ${ }^{\mathrm{b}}$ percentages of total COVID-19 patients.

Table 2 Clinical details of patients who underwent endoscopic interventions as emergency and after waiting period $(n=14)$

\begin{tabular}{|c|c|c|c|c|c|}
\hline No. & Age & Sex & Indication & Procedure & Outcome \\
\hline 1 & 75 & $\mathrm{M}$ & Sigmoid volvulus & Colonoscopic decompression & Emergency, before RT PCR \\
\hline 2 & 54 & M & Variceal bleed & EVL & Emergency, before RT PCR \\
\hline 3 & 39 & $\mathrm{M}$ & Cholangitis-distal CBD stricture & ERCP-CBD stent & Emergency, before RT PCR \\
\hline 4 & 60 & M & Lower GI bleed-diverticular bleed & Colonoscopic hemoclip application & Emergency \\
\hline 5 & 47 & M & Cholangitis-choledocholithiasis & ERCP with CBD clearance & Emergency ERCP, before RT PCR \\
\hline 6 & 58 & M & $\begin{array}{l}\text { Gl bleed-Dieulafoy's lesion with } \\
\text { obstructive jaundice } \\
\text { Post Whipples surgery for carcinoma } \\
\text { head of pancreas }\end{array}$ & $\begin{array}{l}\text { Endoscopic hemoclip application } \\
\text { ERCP-unsuccessful }\end{array}$ & $\begin{array}{l}\text { Emergency, before RT PCR } \\
\text { PTBD for obstructive jaundice } \\
\text { Died after } 10 \text { days due to ARDS }\end{array}$ \\
\hline 7 & 33 & M & ANP with multiple WONs & $\begin{array}{l}\text { Endoscopic nasojejunal tube } \\
\text { placement } \\
\text { Per cutaneous drainage for WON }\end{array}$ & $\begin{array}{l}\text { Emergency } \\
\text { Died to sepsis }\end{array}$ \\
\hline 8 & 33 & $\mathrm{~F}$ & Chronic pancreatitis & $\begin{array}{l}\text { ERCP-pancreatic duct stent } \\
\text { placement }\end{array}$ & Underwent after 2 weeks \\
\hline 9 & 65 & M & Gastric GIST & Diagnostic EUS & $\begin{array}{l}\text { Underwent EUS after } 2 \text { weeks-sur- } \\
\text { gery planned }\end{array}$ \\
\hline 10 & 3 & $\mathrm{~F}$ & Esophageal stricture & Endoscopic dilatation & Underwent after 3 weeks \\
\hline 11 & 60 & $\mathrm{M}$ & Mass lesion in head of pancreas & EUS-FNB & $\begin{array}{l}\text { RT PCR (day } 1 \text { and day } 14) \text { : } \\
\text { negative; } \\
\text { CT-CO-RADS (day } 2): 5 \\
\text { EUS on day } 15\end{array}$ \\
\hline 12 & 70 & $\mathrm{M}$ & $\begin{array}{l}\text { Carcinoma lower 3rd esophagus-on } \\
\text { chemo and radiotherapy }\end{array}$ & Esophageal SEMS & $\begin{array}{l}\text { CT-CO-RADS 3; } \\
\text { RT-PCR: negative } \\
\text { Currently on nasojejunal tube } \\
\text { feeding-planned for SEMS }\end{array}$ \\
\hline 13 & 59 & $\mathrm{~F}$ & Choledocholithiasis & ERCP-CBD clearance & Underwent after 14 days \\
\hline 14 & 43 & $\mathrm{~F}$ & $\begin{array}{l}\text { Gall stones with altered liver function } \\
\text { test }\end{array}$ & EUS & $\begin{array}{l}\text { Developed acute pancreatitis in } \\
\text { waiting period on } 12 \text { th day } \\
\text { RT PCR (day } 14 \text { ): negative } \\
\text { EUS-CBD anechoic (day } 14 \text { ) }\end{array}$ \\
\hline
\end{tabular}

Abbreviations: ANP, acute necrotizing pancreatitis; ARDS, acute respiratory distress syndrome; CBD, common bile duct; CO-RADS, COVID-19 reporting and data system; CT, computed tomography; ERCP, endoscopic retrograde cholangiopancreatography; EUS, endoscopic ultrasound; EVL, endoscopic variceal ligation; GI, gastrointestinal; GIST, gastrointestinal stromal tumor; PTBD, percutaneous transhepatic biliary drainage; RT PCR, real-time polymerase chain reaction; SEMS, self-expanding metal stent; WON, walled-off necrosis.

emergency endoscopies before RT PCR results. Three out of these five patients underwent CT chest prior to endoscopy, which was not suggestive of COVID-19 (CO-RADS 1 or 2). In the remaining 12 patients, intervention has not yet been performed, and clinical details are summarized in - Table 3. One patient with alcohol-related liver cirrhosis along with hepatocellular carcinoma (Barcelona Clinic Liver Cancer [BCLC] stage D) and recurrent variceal bleed was scheduled for emergency endoscopy. However, the patient refused to undergo the procedure.

Two deaths were seen in patients who underwent emergency interventions. One was post Whipple's pancreatoduodenectomy for carcinoma pancreas in a patient who presented with upper GI bleed due to Dieulafoy's lesion for which endoscopic hemoclip application was done. In the same patient, endoscopic retrograde cholangiopancreatography (ERCP) 
Table 3 Clinical details of patients who did not underwent endoscopic intervention $(n=12)$

\begin{tabular}{|c|l|l|l|l|l|}
\hline No. & Age & Sex & Indication & Procedure & Outcome \\
\hline 1 & 4 & M & Esophageal stricture post-surgery & Endoscopic dilatation & Postponed \\
\hline 2 & 33 & F & Achalasia cardia & POEM & Postponed \\
\hline 3 & 50 & F & Submucosal lesion in lower esophagus & Diagnostic EUS & Postponed \\
\hline 4 & 44 & M & Variceal eradication & EVL & Postponed \\
\hline 5 & 49 & F & $\begin{array}{l}\text { Recurrent pain abdomen-lleocecal } \\
\text { Koch's or Crohn's disease }\end{array}$ & lleocolonoscopy & Postponed \\
\hline 6 & 51 & M & Peutz-Jeghers syndrome & Colonoscopy & Postponed \\
\hline 7 & 58 & M & Variceal eradication & EVL & Postponed \\
\hline 8 & 70 & M & Recurrent variceal bleed-Advanced HCC & EVL & patient refused \\
\hline 9 & 45 & F & Chronic pancreatitis & ERCP-Pancreatic duct stent & Postponed \\
\hline 10 & 54 & M & Chronic pancreatitis with calculi in head & ESWL and ERCP & Postponed \\
\hline 11 & 46 & M & Chronic pancreatitis with Pseudocyst & $\begin{array}{l}\text { UGIE nasojejunal tube } \\
\text { placement }\end{array}$ & Postponed \\
\hline 12 & 50 & M & Postradiation esophageal stricture & Endoscopic dilatation & Postponed \\
\hline
\end{tabular}

Abbreviations: ERCP, endoscopic retrograde cholangiopancreatography; ESWL, extra corporeal shock wave lithotripsy; EUS, endoscopic ultrasound; EVL, endoscopic variceal ligation; POEM, per oral endoscopic myotomy; UGIE, upper gastrointestinal endoscopy.

was attempted for obstructive jaundice. It was unsuccessful due to altered anatomy for obstructive jaundice. He underwent percutaneous transhepatic biliary drainage and died due to acute respiratory distress syndrome on account of COVID-19 on the 10th day of admission. The other patient with acute necrotizing pancreatitis had multiple infected walled-off necroses (WON). He underwent percutaneous drainage for WON and endoscopic nasojejunal tube placement for feeding. He died due to septic shock on the 7th day of admission. In one patient with symptomatic gallstones and altered liver function test (LFT), endoscopic ultrasound (EUS) was postponed for 2 weeks. She developed acute pancreatitis on the 12th day. EUS was performed on the 14th day after repeat RT PCR was negative. EUS revealed dilated anechoic common bile duct with acute pancreatitis without local complication and no ERCP was required.

\section{Discussion}

In the current study, we have shown clinical impact of universal COVID-19 testing before therapeutic endoscopy. This study shows that prevalence of COVID-19 infection in the patients undergoing therapeutic endoscopy is $3.34 \%$. There were three adverse events in these COVID-19 infected patients. Two deaths occurred in patients who underwent emergency endoscopic intervention, which were unrelated to endoscopic procedure, and one patient developed acute biliary pancreatitis in the waiting period.

A previous study on COVID-19 positivity in asymptomatic ambulatory endoscopy patients at Stanford University Medical Center had shown overall prevalence of $0.20 \%$ $(2 / 999),{ }^{15}$ while a study from Mount Sinai showed 0.96\% (6/623) prevalence in endoscopy patients. ${ }^{14}$ These two studies demonstrated that COVID-19 positivity is a rare event.

The prevalence of COVID-19 in endoscopy patients is higher in the current study (3.34\%). In the Mount Sinai study, no children tested positive for COVID-19. ${ }^{14}$ In our study, two children tested positive for RT PCR, with one of them undergoing endoscopic dilatation for esophageal stricture after 3 weeks.

Endoscopy is considered as aerosol-generating procedure, which imposes the risk of transmission to health care professionals. ${ }^{1,17}$ Use of PPE and universal testing can reduce stress and anxiety in health care professionals. ${ }^{18-21}$ As our study has shown higher positivity rate compared with previous two studies, we recommend universal testing by RT PCR in patients undergoing endoscopic interventions. ${ }^{14,15}$ The proper utilization of universal testing and infection control protocols can help endoscopic centers to reopen and continue regular work during pandemic, in order to provide standard of care to patients.

In case of COVID-19 positivity, it is advisable to postpone nonemergency endoscopic procedure for at least 2 weeks. ${ }^{14}$ In our study, we postponed 19 (73.1\%) procedures for at least two weeks. Seven $(26.9 \%)$ patients underwent the procedure after a minimum 2-week delay. One patient with gall stones and altered LFT developed acute biliary pancreatitis in waiting the period. Seven patients underwent endoscopic intervention as emergency. One patient who had advanced hepatocellular carcinoma with recurrent variceal bleed was scheduled for emergency endoscopy. However, the patient refused to undergo the procedure.

Our study has certain limitations apart from being single center retrospective analysis. We have not studied the economic impact of additional COVID-19 testing prior to endoscopy. Considering the low cost of endoscopy, additional cost of COVID-19 testing in for all patients in India was not considered as cost-effective. ${ }^{22}$ However, with increasing burden of COVID-19 and availability of RT PCR at reduced cost ( $\sim 60 \$$ in April 2020 to $30 \$$ in June 2020), universal testing should be utilized. RT PCR sensitivity is around 70 to $80 \%$, due to which we might have missed few 
cases in pretesting. However, this is the best available test currently. So, universal precautions are mandatory irrespective of RT PCR results. We could not analyze transmission rate in endoscopy staffs.

In case of limited resources, testing of all patients with RT PCR may not be appropriate. We are further analyzing data to stratify all endoscopy patients into high, intermediate, and low risk of COVID-19 as per demographic and social parameters, including history of travel from other cities or state. We are also requesting patients to inform treating physicians at 2 and 4 weeks after procedure regarding appearance of any COVID-19 related symptoms in patients or close contacts.

To conclude, we suggest use of universal testing for COVID-19 by RT PCR before endoscopic intervention.

Endoscopy can be postponed for 2 weeks with marginal risk of adverse events during the waiting period in nonemergency indications. However, local availability of testing, local infection rates, and history of contact with COVID-19 patients are major determinants for developing local protocols and their implementation. ${ }^{23,24}$ Multicenter studies during COVID-19 pandemic are needed to address safety and efficacy of pre-endoscopy testing for COVID-19.

\section{Conflicts of Interest}

None declared.

\section{References}

1 American Society for Gastrointestinal Endoscopy. American Society for Gastrointestinal Endoscopy: guidance for trainees during the COVID-19 pandemic. Gastrointest Endosc 2020; 92(3):748-753

2 Hennessy B, Vicari J, Bernstein B, et al. Guidance for resuming GI endoscopy and practice operations after the COVID-19 pandemic. Gastrointest Endosc 2020;92(3):743747.e1

3 Chiu PWY, Ng SC, Inoue $\mathrm{H}$, et al. Practice of endoscopy during COVID-19 pandemic: position statements of the Asian Pacific Society for Digestive Endoscopy (APSDE-COVID statements) Gut 2020;69(6):991-996

4 Boškoski I, Gallo C, Wallace MB, Costamagna G. COVID-19 pandemic and personal protective equipment shortage: protective efficacy comparing masks and scientific methods for respirator reuse. Gastrointest Endosc 2020;92(3): 519-523

5 Castro Filho EC, Castro R, Fernandes FF, Pereira G, Perazzo H. Gastrointestinal endoscopy during the COVID-19 pandemic: an updated review of guidelines and statements from international and national societies. Gastrointest Endosc 2020; 92(2):440-445.e6

6 CorralJE,HoogenboomSA,KrönerPT,etal.COVID-19polymerase chain reaction testing before endoscopy: an economic analysis. Gastrointest Endosc 2020;92(3):524-534.e6

7 Goenka MK, Afzalpurkar S, Ghoshal UC, Guda N, Reddy N. Impact of COVID-19 on gastrointestinal endoscopy practice in India: a cross-sectional study. Endosc Int Open 2020; 8(7):E974-E979
8 Forbes N, Smith ZL, Spitzer RL, Keswani RN, Wani SB, Elmunzer BJ; North American Alliance for the Study of Digestive Manifestations of COVID-19. Changes in gastroenterology and endoscopy practices in response to the coronavirus disease 2019 pandemic: results from a North American survey. Gastroenterology 2020;159(2):772-774.e13

9 Parasa S, Reddy N, Faigel DO, Repici A, Emura F, Sharma P. Global impact of the COVID-19 pandemic on endoscopy: An International Survey of 252 Centers from 55 countries. Gastroenterology 2020;159(4):1579-1581.e5

10 Rutter MD, Brookes M, Lee TJ, Rogers P, Sharp L. Impact of the COVID-19 pandemic on UK endoscopic activity and cancer detection: a National Endoscopy Database Analysis. Gut 2020; (e-pub ahead of print). doi: 10.1136/gutjnl-2020-322179

11 Zhao H, Lu X, Deng Y, Tang Y, Lu J. COVID-19: asymptomatic carrier transmission is an underestimated problem. Epidemiol Infect 2020;148:e116

12 Lai CC, Liu YH, Wang CY, et al. Asymptomatic carrier state, acute respiratory disease, and pneumonia due to severe acute respiratory syndrome coronavirus 2 (SARS-CoV-2): Facts and myths. J Microbiol Immunol Infect 2020;53(3):404-412

13 Rana SS. Risk of COVID-19 transmission during gastrointestinal endoscopy. J Digest Endosc 2020;11(01):27-30

14 Dolinger MT, Kumta NA, Greenwald DA, Dubinsky MC. Outcomes of universal pre-procedure COVID-19 testing prior to endoscopy in a tertiary care center in New York City. Gastroenterology 2020; (e-pub ahead of print). doi: 10.1053/j. gastro.2020.07.015

15 Podboy A, Cholankeril G, Cianfichi L, Guzman E Jr, Ahmed A, Banerjee S. Implementation and impact of universal preprocedure testing of patients for COVID-19 before endoscopy. Gastroenterology 2020;159(4):1586-1588.e4

16 Prokop M, van Everdingen W, van Rees Vellinga T, et al; COVID-19 Standardized Reporting Working Group of the Dutch Radiological Society. CO-RADS: A categorical CT assessment scheme for patients suspected of having COVID-19 definition and evaluation. Radiology 2020;296(2):E97-E104

17 Repici A, Aragona G, Cengia G, et al; ITALIAN GI-COVID19 Working Group. Low risk of COVID-19 transmission in GI endoscopy. Gut 2020;69(11):1925-1927

18 Siddique SM, Sultan S, Lim JK, et al; AGA. Spotlight: OVID-19 PPE and endoscopy. Gastroenterology 2020;159(2):759

19 Rossi R, Socci V, Pacitti F, et al. Mental health outcomes among frontline and second-line health care workers during the Coronavirus disease 2019 (COVID-19) pandemic in Italy. JAMA Netw Open 2020;3(5):e2010185

20 Lai J, Ma S, Wang Y, et al. Factors associated with mental health outcomes among health care workers exposed to Coronavirus disease 2019. JAMA Netw Open 2020;3(3):e203976

21 Tandan M, Jagtap N. Be aware, be alert, be prepared: endoscopy during the COVID-2019 pandemic. J Digest Endosc 2020;11(01):59-60

22 Sundaram S. COVID-19 testing before every endoscopy: Is India ready for prime time? Gastrointest Endosc 2020;92(3):789-791

23 Hayee B, Thoufeeq M, Rees CJ, Penman I, East J. Safely restarting GI endoscopy in the era of COVID-19. Gut 2020; (e-pub ahead of print). doi: 10.1136/gutjnl-2020-321688

24 Lakhtakia S, Ramchandani M. Triaging patients undergoing endoscopy during COVID-19 pandemic. J Digest Endosc 2020; 11(01):41-43 